\title{
Encontrando-se em casa: uma proposta de atendimento domiciliar para famílias de idosos dependentes*
}

\author{
Meeting at home: a proposal of home attendance for families of dependent seniors \\ Encontrándose en casa: una propuesta de atención en el domicilio para las familias de ancianos \\ dependientes
}

\author{
Lucía Silva $^{1}$, Sueli Aparecida Frari Galera ${ }^{2}$, Vânia Moreno ${ }^{3}$
}

\begin{abstract}
RESUMO
Objetivo: Este estudo qualitativo teve por objetivo descrever como um sistema familiar reage perante a situação de dependência em um membro idoso, quais recursos utiliza para manter sua estabilidade e a assistência de enfermagem disponibilizada neste contexto. Métodos: Utilizou-se como referencial teórico a abordagem dos sistemas familiares e como método a pesquisa-ação. Os dados foram colhidos de novembro de 2004 a janeiro de 2005, utilizando-se o genograma, o ecomapa e o levantamento de problemas. Resultados: Principais demandas familiares: luto antecipado, sobrecarga do papel de cuidador, falta de conhecimento sobre a doença e desajustamento familiar perante a crise. Principais intervenções: incentivar a narrativa da enfermidade, oferecer sugestões e informações, elogiar as forças familiares e assegurar pronto atendimento. Conclusões: Com o atendimento à família sob o enfoque sistêmico foi possível propor as intervenções de ajuda para a melhoria da qualidade de vida familiar, de maneira que ela também vislumbrasse suas próprias soluções para o enfrentamento das adversidades.
\end{abstract}

Descritores: Relações familiares; Assistência domiciliar; Assistência a idosos; Enfermagem familiar

\begin{abstract}
Objective: This qualitative study intends to identify how a family system reacts before the situation of dependence of a senior family member, which resources it uses to maintain the stability and the nursing attendance made available in this context. Methods: The approach of the family systems was used as the theoretical reference, and action-research as the method. The data were collected in the period from November/2004 to January/2005, through the construction of a genogram, an ecomap and problem definition. Results: Main family demands: anticipated mourning, overload on the role of caregiver, lack of knowledge regarding the disease and family maladjustment before the crisis. Main interventions: motivating the family to speak openly about the illness, offering suggestions and information, praising the family strength and ensuring prompt service. Conclusions: With family attendance as the systemic focus, it was possible to propose healthcare interventions to improve the quality of family life so as they could devise their own solutions to face adversities.
\end{abstract}

Keywords: Family relations; Homecare nursing; Old age assistance; Family nursing

\section{RESUMEN}

Objetivo: En este estudio cualitativo se tuvo como objetivo describir cómo un sistema familiar reacciona frente a una situación de dependencia de un miembro anciano, qué recursos utiliza para mantener su estabilidad y la asistencia de enfermería disponible en este contexto. Métodos: Se utilizó como referencial teórico el abordaje de los sistemas familiares y como método la investigación acción. Los datos fueron recogidos desde noviembre del 2004 a enero del 2005, utilizándose el genograma, o ecomapa y el levantamiento de problemas. Resultados: Principales demandas familiares: duelo anticipado, sobrecarga del papel de cuidador, falta de conocimiento sobre la enfermedad y desajuste familiar frente a la crisis. Principales intervenciones: incentivar a la familia a la narración de la enfermedad, ofrecer sugerencias e informaciones, elogiar las fuerzas familiares y asegurar la atención rápida. Conclusiones: Con la atención a la familia bajo el enfoque sistémico fue posible proponer las intervenciones de ayuda para la mejoría de la calidad de la vida familiar, de manera que ella también vislumbre sus propias soluciones para el enfrentamiento de las adversidades.

Descriptores: Relaciones familiares; Asistencia domiciliaria; Asistencia al anciano; Enfermería familiar

* Trabalho baseado na Dissertação de Mestrado apresentada à Escola de Enfermagem de Ribeirão Preto da Universidade de São Paulo - USP - Ribeirão Preto (SP), Brasil; subsidiada pelo Conselho Nacional de Desenvolvimento Científico e Tecnológico (CNPq).

${ }^{1}$ Pós-graduanda em Enfermagem, Professora do Curso de Graduação em Enfermagem da Faculdade Marechal Rondon - UNINOVE - São Manuel (SP), Brasil.

${ }^{2}$ Doutora, Professora da Escola de Enfermagem de Ribeirão Preto da Universidade de São Paulo - USP - Ribeirão Preto (SP), Brasil.

${ }^{3}$ Doutora, Professora Assistente do Departamento de Enfermagem da Faculdade de Medicina da Universidade Estadual Paulista "Júlio de Mesquita Filho"UNESP - Botucatu (SP), Brasil. 


\section{INTRODUÇÃO}

No Brasil, o envelhecimento da população assume características peculiares dada a rapidez com que vem se instalando. De acordo com os padrões estabelecidos pela Organização Mundial de Saúde, o país já pode ser considerado estruturalmente envelhecido, dado que mais de $7 \%$ de sua população possui hoje 60 ou mais anos de idade $^{(1)}$.

Essa mudança demográfica faz com que o envelhecimento ganhe destaque no cenário nacional, no qual os aspectos culturais também são considerados e não apenas os aspectos biológicos da velhice ${ }^{(2)}$.

Nessa etapa da vida ocorrem alterações funcionais que, embora variem de um indivíduo a outro, são encontradas em todos os idosos e são próprias do processo de envelhecimento natural, acarretando, portanto, em maior predisposição do indivíduo ao surgimento de condições crônicas de saúde e suas possíveis seqüelas debilitantes.

Assim, também é de se esperar que aumente o número de idosos dependentes inseridos nos meios social e familiar.

A redução dos custos com a assistência hospitalar e institucional é um dos motivos que faz com que, tanto no Brasil quanto em muitos outros países, a permanência dos idosos incapacitados em suas próprias casas, sob os cuidados de sua família, seja indicada. Além disso, a visão atual da assistência em saúde propõe que o idoso acometido por uma condição crônica e com incapacidades deve ser cuidado no ambiente onde sempre viveu e adoeceu.

Contudo, esta postura pode ser considerada um tanto idealista, visto que a família vem sofrendo diversas modificações na sociedade atual, e nem sempre tem condições de assumir responsabilidades pelo cuidado do idoso que, por exemplo, pode exigir que um membro da família deixe de trabalhar.

Além disso, o fato de vivenciar a possibilidade da perda também pode ser um aspecto que dificulte os cuidados por parte do familiar, caso o idoso tenha valores em relação ao seu corpo e não se sinta à vontade com uma filha dando-lhe o banho. Esses exemplos nos indicam que, para poder cuidar do seu idoso, a família precisa ser incluída no plano de cuidados do profissional de saúde; é preciso que sejam adotadas medidas como, prever horas de descanso e momentos em que o cuidado deve ser oferecido por profissionais.

A finalidade deste trabalho é apresentar uma intervenção de enfermagem fundamentada no modelo Calgary, que adota a família como unidade de cuidado.

Quando considerarmos a família como um sistema, ou seja, como uma unidade na qual é possível visualizar a interação entre seus membros, a presença de um idoso dependente afeta todos os componentes do grupo e, dependendo da cultura familiar, o envelhecimento e a dependência são percebidos de diversas maneiras. Daí a necessidade de os profissionais de saúde levarem em consideração a estrutura e a cultura da família, ao proporem os cuidados ao idoso.

Diante do exposto, o objetivo desse trabalho foi descrever como uma família reage perante a situação de dependência em um membro idoso, quais recursos utiliza para manter sua estabilidade e quais intervenções de enfermagem podem ser úteis e aplicáveis neste contexto.

\section{MÉTODOS}

Neste estudo qualitativo utilizou-se como referencial teórico a abordagem dos sistemas familiares no referencial sistêmico ${ }^{(3)}$ e, como método de trabalho, adotou-se a pesquisa-ação, na qual pesquisadores e participantes representativos da situação ou do problema estão envolvidos de modo cooperativo e participativo ${ }^{(4)}$. Utilizamos um modelo de avaliação e de intervenção fundamentado no modelo de Calgary, um pouco simplificado. Depois de estudar o modelo e o formulário dele derivado, escolhemos uma família com a qual seria aplicado o modelo para nortear a avaliação da família e as intervenções de enfermagem adotadas.

Participaram dessa experiência uma das autoras responsável pelo desenvolvimento dos encontros (chamada aqui pesquisadora principal) e uma supervisora, também co-autora da experiência, e três membros de um grupo familiar do qual fazia parte uma idosa dependente apresentando doença mental - esquizofrenia há mais de 20 anos e insuficiência renal crônica, diagnosticada há três meses, assistida por uma Unidade de Saúde da Família (USF) do interior paulista.

Após aprovação do Comitê de Ética em Pesquisa da Faculdade de Medicina de Botucatu - UNESP, no período de novembro de 2004 a janeiro de 2005 os dados foram colhidos em cinco encontros no domićlío da família, após a assiantura do termo de Consentimento Livre e Esclarecido, através da construção de genograma, ecomapa, levantamento de problemas e diário de campo, para o registro das interações. Os dados obtidos foram analisados de acordo com o modelo interativo de análise de $\operatorname{dados}^{(5)}$.

\section{RESULTADOS}

Ressalta-se que a cada um dos participantes foi conferido um nome fictício, a fim de resguardar-lhes a identidade.

\section{Apresentando a família de D. Alice}

Chegou-se à família de D. Alice por meio da agente 
comunitária de saúde que relatava a insistência de sua filha em solicitar visitas domiciliares para a mãe, dependente de cuidados por ser idosa acometida por doença renal há três meses.

Segundo verbalizado pela agente, a filha Ana procurava o serviço com insistência afirmando que o Programa de Saúde da Família (PSF) tinha a obrigação de ir até a casa para ver sua mãe, visto que preconiza o atendimento médico no domicílio. Entretanto, toda vez que a equipe ia ao domicílio, verificava que a idosa mantinha estado de saúde satisfatório e não necessitava de mais cuidados além dos que já estavam sendo oferecidos.

Desse modo, segundo a agente, quando a equipe realizava a visita domiciliar, constatava que D. Alice apresentava exames clínicos e laboratoriais dentro dos padrões aceitáveis para sua doença, não justificando a insistência da filha em receber as visitas. Buscou-se, então conhecer e compreender que outras demandas estariam relacionadas ao acionamento da equipe do PSF por parte da filha da paciente.

Esta situação representa aquilo que alertamos sobre o olhar idealizado que o profissional tem da família. Escolhemos esta família porque, apesar de oferecer a ida até a casa, o profissional de saúde não atendia às necessidades verbalizadas pela filha; ela continuava indo ao serviço solicitar visita.

Nossa primeira intervenção, portanto, foi conversar com a filha Ana e, não, ver a idosa. Neste momento, ampliamos nosso enfoque, ajustamos nossas lentes ao contexto do idoso. Inclusão e escuta são intervenções poderosas nesse momento ${ }^{(3)}$.

Foram realizados cinco encontros dos quais participaram Ana* - a filha da paciente, Sr Alberto* - seu esposo, Ângela* - a sobrinha, a enfermeira pesquisadora e a enfermeira psiquiátrica supervisora. Ana foi a única que participou dos cinco encontros.

\section{A estrutura familiar}

A paciente, D. Alice, tem 61 anos, apresenta esquizofrenia há 20 anos e insuficiência renal crônica, diagnosticada há três meses. Seu marido, Sr Benedito, 65 anos, é lavrador aposentado. Eles têm uma única filha, Ana, 29 anos, empregada doméstica desempregada, casada com Alberto, 24 anos, entregador. Juntos, têm dois filhos: Bruno, sete anos e Alfredo, dois anos. A partir dessas informações, foi construído o genograma (Figura 1), buscando conhecer a estrutura interna da família de Alice.

Os relacionamentos da família com os sistemas mais amplos, ou seja, sua estrutura externa, foram apreendidos com a construção do ecomapa (Figura 2).

D. Alice realiza sessões de hemodiálise três vezes por semana, no hospital universitário, sendo essa sua única saída de casa. Sr Benedito freqüenta rotineiramente um bar localizado no centro da cidade, onde costuma encontrar os amigos. Também costuma ir ao banco para receber sua aposentadoria e à UFS, quando se sente "doente".

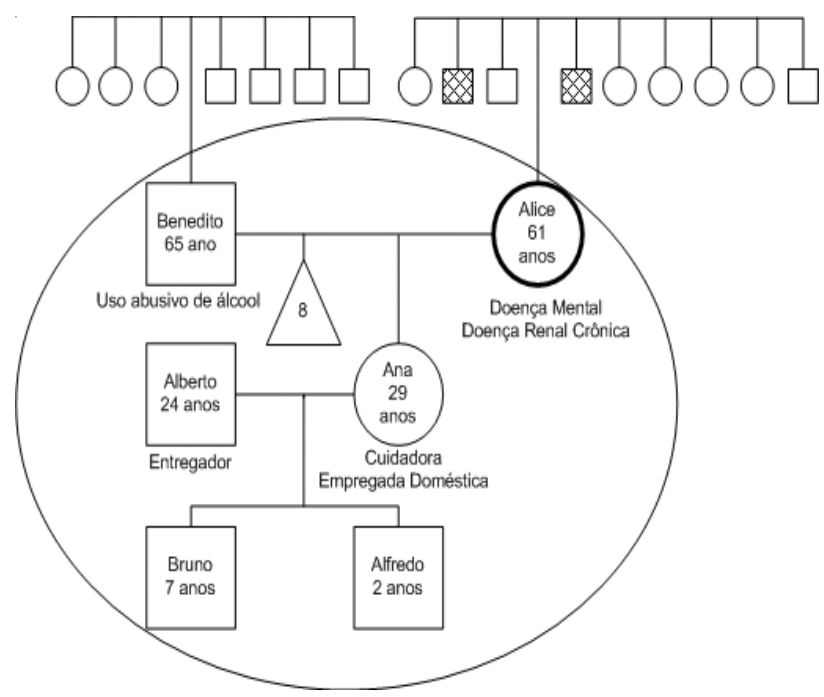

Figura 1 - Genograma da família de D. Alice

\section{Legenda:}

Homem

Mulher $\bigcirc$

Casamento

Morte

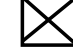

Pessoa índice

Aborto $\triangle$

Adaptado de Wright \& Leahey, 2002(3).

Ana freqüenta regularmente a USF para cuidar de sua saúde e da de seus filhos e, quando está trabalhando, mantém vínculo com o local de seu emprego. Os relacionamentos de Alberto são com os amigos do bar e com seus colegas de trabalho. Ana e seu esposo mantêm contato com os tios e primos da linhagem paterna.

A família mora em um bairro com problemas sociossanitários relevantes, cuja população apresenta baixo poder aquisitivo. No terreno comum em que vivem existe a casa em que D. Alice mora com Sr. Benedito e, ao fundo, a casa em que Ana vive com Alberto e as crianças. Ambas são simples, possuem quatro cômodos cada uma, iluminação natural insuficiente, mobília mínima necessária e condições higiênicas satisfatórias.

O grupo familiar de seis pessoas vivia da aposentadoria do Sr Benedito, da renda de Alberto como entregador e do salário de Ana como faxineira, sendo o rendimento 
familiar mensal de pouco mais de três salários mínimos.

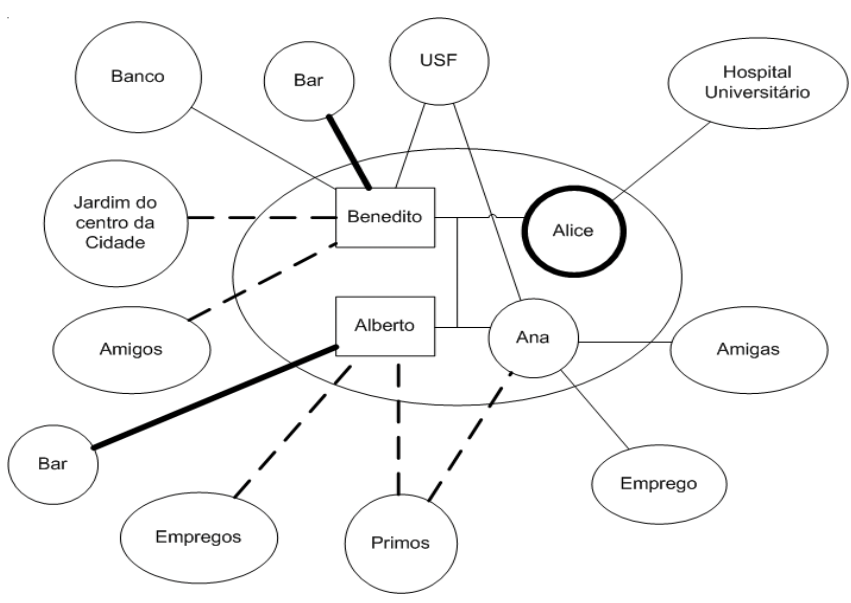

Figura 2 - Ecomapa da família de D. Alice.

\section{Legenda:}

Vínculo moderado

Vínculo intenso

Vínculo muito intenso

Vínculo fraco

Vínculo estressante

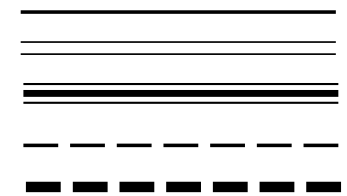

Adaptado de Wright \& Leahey, $2002^{(3)}$.

Sr. Benedito sente-se bem com o fato de poder contribuir financeiramente com a casa; orgulha-se de comprar remédios não fornecidos pela USF, alimentos e roupas para a família.

D. Alice e Sr. Benedito não possuem estudo algum. Ana e Alberto possuem o segundo ciclo do ensino fundamental incompleto. O filho mais velho de Ana freqüenta a primeira série do ensino fundamental, enquanto o caçula ainda não vai à escola.

Todos os integrantes da família são católicos. Apesar de não freqüentarem a igreja, têm fé e recorrem a Deus para o enfrentamento de momentos difíceis.

\section{O desenvolvimento familiar}

Em relação ao ciclo de vida familiar, ou seja, à divisão do desenvolvimento das famílias em estágios, com suas tarefas peculiares e modelos de interação que se repetem através das gerações, identificou-se no grupo familiar duas fases dos estágios da vida: "a família com filhos pequenos" e "a família no estágio tardio da vida"(()). Esta é uma família que se assemelha às famílias mais antigas, onde convivem várias gerações.

Em relação ao estágio "a família com filhos pequenos", é esperado que o sistema conjugal se una nas tarefas de educação dos filhos, nas tarefas financeiras e domésticas e que haja um realinhamento dos relacionamentos com a família ampliada para incluir os papéis de pais e avós ${ }^{(6)}$. $\mathrm{Na}$ familia estudada, a responsabilidade e o atendimento às demandas das crianças são superados principalmente por Ana, sem maiores dificuldades.

No estágio tardio de vida, o princípio-chave é aceitar a mudança dos papéis geracionais, como apoiar um papel mais central da geração mais nova ${ }^{(6)}$. Provavelmente por esse motivo, é importante para o Sr. Benedito colaborar financeiramente; sua contribuição o coloca em uma posição importante, centrada no papel provedor.

O desenvolvimento do modelo hegemônico de família nuclear se concretiza na maioria dos lares: a autoridade masculina concentra-se na figura do chefe de família, que assenta sua legitimidade na condição de provedor financeiro ${ }^{(7)}$.

Ana reconhece a importância do papel do pai, contudo, preocupa-se com sua saúde: é hipertenso, apresenta glaucoma e faz uso abusivo de bebida alcoólica.

Há uma interdependência apropriada entre a geração mais velha e a geração subseqüente: Sr. Benedito é capaz de ajudar a filha e esta tem a responsabilidade do cuidado dos pais, principalmente da mãe dependente. Apesar de o envelhecimento normalmente estar associado à improdutividade, os idosos parecem ter a mesma probabilidade de ajudar e apoiar seus filhos, a exemplo do constatado no presente estudo ${ }^{(3)}$.

D. Alice, por sua vez, apresenta esquizofrenia e é totalmente dependente da filha, principalmente pela condição degenerativa da doença renal crônica, diagnosticada recentemente - Ana relaciona essa dependência quase que total da mãe (não se comunicar, não se banhar e não se alimentar sozinha) ao aparecimento da insuficiência renal. A partir desse diagnóstico, a família, que mantinha certa estabilidade, passa a se desestruturar: há uma acentuada sobrecarga do papel de cuidadora que Ana realiza, a situação de uso abusivo de álcool por parte do Sr. Benedito e a preparação da família para a perda materna.

Apesar de ser muito discutível a indicação de hemodiálise para idosos com severo comprometimento cognitivo, esta opção foi feita pela equipe do hospital universitário da cidade.

Para o Sr. Benedito, o fato de D. Alice passar pelas sessões de hemodiálise semanalmente apenas prolonga o sofrimento da família, visto que a doença renal já encontra-se bastante avançada. Além da questão da terminalidade, ou seja, da idosa estar fora de possibilidade terapêutica de cura, a família também vivencia a questão da finitude, já que a paciente em questão encontra-se no estágio tardio de vida. Nessa fase, parte do estresse familiar ocorre pelo impacto da dependência do idoso sobre a família, e parte é decorrente da preparação da família para a morte $^{(8-9)}$. 


\section{O funcionamento familiar}

Às atividades da vida diária da família, como alimentação, higiene, sono, trabalho, cuidado com as crianças, etc, somam-se as relacionadas à dependência de D. Alice, realizadas diariamente pela filha Ana: preparo e oferta de dieta especial, curativo diário em cateter venoso e em úlcera de membro inferior, administração de medicação, banho e hemodiálise três vezes por semana.

No tocante ao funcionamento familiar expressivo ou afetivo, pôde-se verificar que todos os cuidados oferecidos à D. Alice ficam sob a responsabilidade de Ana. Segundo ela, o pai e o esposo não são tão capazes para fazê-lo pelo fato de serem homens, o que pode ser explicado pela questão de gênero, permeada por um conjunto de crenças sobre as expectativas de condutas e experiências femininas e masculinas ${ }^{(3)}$.

Sr. Benedito diz ser uma pessoa triste e constantemente nervosa. Segundo Ana, isso ocorre pelo fato de ele não compreender bem a doença da esposa e por não suportar o fato do genro falar e escutar som muito alto. Pensando esta relação entre sogro e genro de modo interacional, Sr. Benedito sente-se humilhado e desrespeitado pelo genro e faz críticas ao seu comportamento. Por causa das críticas, é visto como "resmungão", gerando impaciência por parte de Alberto que mantém seu comportamento, desprezando o sogro. Ana não se importa com a responsabilidade pelo cuidado de sua mãe, lamentando apenas o fato de seu pai e seu esposo viverem em constante conflito. Para ela, filha única, houve todo um cuidado especial para que nascesse e agora interpreta isso como sendo a sua vez de cuidar da mãe. Essa é uma crença que tem um papel facilitador para o desenvolvimento de soluções para os problemas.

\section{Apresentando os encontros em casa}

O primeiro encontro ocorreu com o intuito de iniciar a construção do genograma, ecomapa e levantamento de problemas.

A princípio, Ana refere que não tem dificuldades em lidar com a situação, lamentando o fato de seu pai ser muito "nervoso", não gostar de barulho e não conversar com o genro. Em relação ao esposo, relata que o mesmo não tem compromisso com a família por ser mais jovem; ele não percebe a questão da dependência da sogra como um problema que mereça sua atenção.

Assim, todo o cuidado da mãe fica sob sua responsabilidade, praticamente desde os nove anos de idade. Naquela época seu pai trabalhava na roça e D. Alice sofria de "ataque de nervos" e era internada em instituições psiquiátricas.

Devido aos cuidados que dispensa à mãe, nem sempre é possível que Ana se divirta, mesmo gostando de receber os amigos. Ela também tem dificuldade para conseguir trabalho remunerado por causa de suas responsabilidades com a mãe.
Os problemas familiares identificados giraram em torno da sobrecarga do papel de cuidadora incorporado por Ana e os conflitos entre sogro e genro. As intervenções de enfermagem foram discutir a (re) inserção do lazer e do trabalho em sua vida e a colocação de limites e responsabilidades para seu pai e seu esposo, tanto no tocante à casa quanto nas próprias relações familiares.

$\mathrm{O}$ segundo encontro aconteceu com a finalidade de concluir o genograma e o ecomapa e aprofundar a discussão do relacionamento familiar.

Ana contou que antes do seu nascimento, D. Alice já havia sofrido oito abortos e um óbito fetal por não realizar acompanhamento médico durante as gestações. Quando engravidou de Ana, ela e o marido optaram por se submeterem aos cuidados médicos e a gravidez e o parto ocorreram sem intercorrências.

Dessa maneira, para Ana, houve um empenho para que ela nascesse e agora ela se sente na obrigação de retribuir cuidando da mãe. Acredita que Deus já havia traçado este plano e permitiu que ela nascesse para posteriormente cuidar de sua mãe e, assim, o faz de coração aborrecendo-se apenas com os conflitos entre seu pai e seu esposo.

Pode-se perceber que Ana tem um papel familiar conflituoso, visto que divide-se entre os cuidados à mãe e a servir seu marido, dividindo-se entre os papéis de filha e esposa. A crença de Ana na sua vocação de cuidadora contribui para que ela se responsabilize por sua mãe, porém esta mesma crença não permite admitir a necessidade de dividir suas responsabilidades com outros membros da casa.

Ana acredita que a sobrecarga emocional a que está constantemente submetida em virtude dos desentendimentos familiares pode desencadear o desenvolvimento de algum tipo de "problema de cabeça", como o de sua mãe.

Para Ana, esse tipo de problema poderia ser hereditário visto que alguns familiares de sua linhagem materna também o possuíam. Essa sua preocupação está intimamente ligada ao luto antecipado vivido pela família: tendo a doença um caráter hereditário, Ana poderia ser a próxima a adoecer após a morte de sua mãe.

Ana informou que se entristece com o fato de não conversar muito com o seu pai e quando o faz, a comunicação acontece em caráter de cobrança, no sentido de saber onde ele esteve durante o dia. Relata que se preocupa quando seu pai fica no bar, e anda fazendo uso abusivo de bebida alcoólica.

Com relação às mudanças ocorridas na família desde o último encontro, Ana relatou que conseguiu um emprego como diarista, trabalhando três vezes por semana, dias em que Sr. Benedito ficaria responsável pelo cuidado das crianças.

As intervenções de enfermagem foram: completar a construção do genograma, ecomapa e oferecimento de informações sobre a doença mental e suas possíveis causas, 
desmistificando a crença de que a mesma seria apenas hereditária. Diante da dificuldade de comunicação entre Ana e o pai, sugerimos que, quando o mesmo chegasse da rua não alcoolizado, ela procurasse abordá-lo perguntando, por exemplo, como havia sido o passeio, com o intuito de que tivessem a possibilidade de conversar. Também foi ressaltada a iniciativa de Ana estar trabalhando.

No terceiro encontro Ana trouxe que o relacionamento entre o pai e o esposo estava mais tranqüilo e que ela também estava mais calma. Acredita que isso tenha sido possível em decorrência das próprias atitudes do grupo, de se respeitarem mutuamente, e dos atendimentos domiciliares, que possibilitaram que eles mesmos visualizassem como suas interações poderiam prejudicar a harmonia do grupo.

Sua prima Ângela relatou estar muito aflita com a possibilidade do segundo episódio no ano de uma infecção ginecológica evoluir para uma "doença grave" e, então, Ana aproveita o assunto para contar que, desde que teve seu primeiro filho, há sete anos, sente muitas dores no momento da relação sexual. Diz que por causa das dores, nem sempre consegue levar a relação adiante e por mais que o marido "às vezes tenha paciência, ele é jovem”. Relata já ter procurado vários serviços, e que sempre acatou as orientações médicas, sem obter sucesso.

Foram realizadas as seguintes intervenções: ressaltar que a iniciativa de Ana em trabalhar fora de casa foi muito importante para o padrão de relacionamento familiar, tranqüilizar e conscientizar a prima de que seria necessário que ela priorizasse o tratamento adequado da infecção e averiguar a possibilidade de atendimento ginecológico o mais rápido possível. Também discutimos brevemente sobre a possibilidade de Ana, após o término das sessões, ter um espaço para psicoterapia, no qual pudesse repensar sua relação com os pais e com o esposo, por exemplo.

Realizou-se o quarto encontro objetivando discutir mais profundamente a dificuldade de relacionamento entre $\mathrm{Sr}$. Benedito e Alberto. Sr. Benedito faz críticas ao comportamento tanto do genro como de sua família, que têm o costume de falarem alto e usarem termos ofensivos.

Relata que, às vezes, sente-se muito triste, apresentando dificuldades para dormir e há algum tempo está fazendo uso de bebida alcoólica para sentir-se melhor, mas ressalta que "não é bêbado" e que nunca deixou faltar nada (alimentos, roupas) em casa.

Ana reforça que seu pai a ajuda sempre que necessário (roupas para as crianças, remédios, perfumaria) e que ela então fica responsável pelos cuidados com a mãe, percebendo a situação como uma "troca", uma "ajuda mútua", mas assim mesmo preocupa-se com a saúde de seu pai.

Essa solidariedade pode ser definida como um sentimento despertado na família pela relação de responsabilidade entre pessoas unidas por laços de afetividade, determinando o apoio a um membro que esteja vivenciando o processo de tratamento de uma doença, como uma obrigação moral ${ }^{(10)}$.

Foram realizadas as intervenções: ressaltar a força de Sr. Benedito em permanecer todos estes anos ao lado de sua família, mesmo diante das dificuldades da doença de sua esposa, explicação de que sua tristeza poderia decorrer do sofrimento pelo qual passou durante anos, orientar sobre maneiras de redução de danos do uso abusivo do álcool, discutir a possibilidade de ele submeter-se a um atendimento de saúde mental e, conforme combinado no encontro anterior, Ana foi encaminhada para dar início à psicoterapia em um centro de saúde de referência, após o término dos atendimentos.

No quinto encontro Sr. Benedito mostrou-se irritado com a possibilidade de passar por um atendimento de saúde mental e dizia que não tinha "problema de cabeça". Ana argumentou que não se tratava disso e sim de cuidar da mente, assim como cuidam da saúde do corpo.

Como este era o último encontro, Ana disse que achou boa a proposta desse tipo de atendimento, uma vez que pôde entender melhor a doença mental e passou a compreender melhor e ter mais paciência com as alterações de humor de seu pai.

Para ela, nós, "profissionais da saúde", fomos capazes de apreender melhor a situação de sua casa. Sentiu-se à vontade para colocar não só os problemas em relação aos seus pais como também seus outros problemas, como a questão ginecológica, e ter esperança de melhora visto que está comparecendo aos retornos. Seu pai disse que ajudou, pois "conversar é bom".

Ana refere que gostaria de conversar mais com seu pai e para ele, isso é recíproco. Relembram que antigamente conversavam mais e davam "boas risadas" e acreditam que isso tenha diminuído por conta das atribulações do dia-a-dia.

As intervenções de enfermagem incluíram as ações: desmistificar o atendimento de saúde mental e sugerir que pai e filha se organizem para conversarem em algum momento do dia em que estejam juntos, como ao fim das atividades e compromissos.

\section{DISCUSSÃO}

As diretrizes operacionais do PSF ressaltam a apreensão da família inserida em seu meio sociocultural como núcleo básico de assistência, sendo fundamental a apreensão da multicausalidade dos agravos à saúde de ordem social, física e mental ${ }^{(11-12)}$. Assim, quando a equipe de saúde da família se depara com uma queixa no contexto familiar, a escuta e o olhar se ampliam para além do enfoque individual e focalizam a família.

Enquanto a equipe de saúde da família estava centrada na queixa biológica, não reconhecia a necessidade de 
intervenção, visto que clinicamente a idosa encontrava-se estável. A partir do momento em que nos propusemos a abordar a família como um todo sob o enfoque sistêmico, foi possível identificar e cuidar do sofrimento familiar gerado pelo contexto.

Com o atendimento à família sob o enfoque sistêmico, foi possível interagirmos com a mesma e realizarmos uma detalhada avaliação do grupo familiar. A partir daí, em parceria com este núcleo, foram propostas as intervenções de ajuda para a melhoria da qualidade de vida familiar, de maneira que a família também vislumbrasse suas próprias soluções para o enfrentamento das adversidades.

Assim, um dos grandes potenciais do PSF reside em sua capacidade de oferecer suporte e fortalecer as famílias que estão sob sua responsabilidade.

\section{CONCLUSÃO}

Este trabalho permitiu ressaltar que não adianta apenas determinar politicamente que a equipe de saúde da família deve abordar a família como unidade de cuidado. É preciso ter instrumentos que habilitem o profissional a adotar essa abordagem.

O referencial sistêmico mostrou-se muito útil na escuta do núcleo familiar como um todo.

A enfermagem tem muito a contribuir na assistência às famílias e esta pesquisa demonstra como a intervenção de enfermagem pode colaborar para a melhora das condições de vida do grupo familiar.

\section{REFERÊNCIAS}

1. Duarte YAO. O processo de envelhecimento e a assistência ao idoso. In: Brasil. Instituto para o Desenvolvimento da Saúde. Manual de enfermagem. Brasília (DF): Ministério da Saúde; 2001. p.185-96.

2. Leibing $\mathrm{A}$. The old lady from Ipanema: changing notions of old age in Brazil. J Aging Stud 2005; 19(1): 15-31.

3. Wright LM, Leahey M. Enfermeiras e famílias: um guia para avaliação e intervenção na família. 3a ed. São Paulo: Roca; 2002.

4. Thiollent M. Metodologia da pesquisa-ação. 4a ed. São Paulo: Cortez; Autores Associados;1988.

5. Noiseux S. Evaluation construtiviste d'une intervention enfermiére auprés d'um couple de parents ayant um enfant em préparation à une greffe de moelle osseuse. Montreal: Mémoire (Maitre ès sciences infermieres). Faculte de Sciences infermieres - Université de Montreal; 1999.

6. Carter B, McGoldrick M, organizadoras. As mudanças no ciclo de vida familiar: uma estrutura para a terapia familiar. $2 \mathrm{a}$ ed. Porto Alegre: Artes Médicas; 1995.

7. Romanelli G. Autoridade e poder na família. In: Carvalho MCB, organizadora. A família contemporânea em debate. 4a ed. São Paulo: EDUC; Cortez; 2002. p.73-88.

8. Walsh F. A família no estágio tardio de vida. In: Carter B, McGoldrick M, organizadoras. As mudanças no ciclo de vida familiar: uma estrutura para a terapia familiar. $2 \mathrm{a}$ ed. Porto Alegre: Artes Médicas; 1995. p.269-87.

9. Rolland JS. Ajudando famílias com perdas antecipadas. In: Walsh F, McGoldrick M, organizadoras. Morte na família: sobrevivendo às perdas. Porto Alegre: Artmed; 1998. p.166-86.

10. Silva L, Bocchi SCM. A sinalização do enfermeiro entre os papéis de familiares visitantes e acompanhante de adulto e idoso. Rev Latinoam Enfermagem. 2005; 13(2): 180-7.

11. Ministério da Saúde. Saúde da Família: uma estratégia para a organização da atenção básica. Brasília (DF): Ministério da Saúde; 2001.

12. Oliveira MAF, Colvero LA. A saúde mental no Programa de Saúde da Família. In: Brasil. Instituto para o Desenvolvimento da Saúde. Manual de enfermagem. Brasília (DF): Ministério da Saúde; 2001. p.198-201. 